\title{
Comment on: “Fluvoxamine for the Early Treatment of SARS-CoV-2 Infection: A Review of Current Evidence"
}

\author{
Mario Gennaro Mazza ${ }^{1,2}$ (D) Benedetta Vai ${ }^{1,2} \cdot$ Livia De Picker $^{3,4} \cdot$ Francesco Benedetti $^{1,2} \cdot$ Raffaella Zanardi $^{1,5}$
}

Accepted: 1 February 2022 / Published online: 12 February 2022

(c) The Author(s), under exclusive licence to Springer Nature Switzerland AG 2022

\section{Dear Editor,}

We read with great interest the Current Opinion paper by Facente et al. [1], who promptly reviewed the available literature assessing fluvoxamine administration as a repurposed drug for the treatment of severe acute respiratory syndrome coronavirus 2 (SARS-CoV-2) infection. The current evidence [2-4] supports the promising role of fluvoxamine as an effective early treatment option for preventing clinical deterioration, hospitalization, mortality, and long-term morbidity due to SARS-CoV-2 infection. This protective effect over severe coronavirus disease 2019 (COVID-19) outcomes can result from potential anti-inflammatory, immune-modulatory, and antiviral mechanisms related to fluvoxamine. Fluvoxamine is a selective serotonin reuptake inhibitor antidepressant, commonly used to treat major depressive disorder and obsessive-compulsive disorder with an efficacy, tolerability, and a side-effect profile similar to other selective serotonin reuptake inhibitors [5]. Even if all the reviewed

This comment refers to the article available online at https://doi. org/10.1007/s40265-021-01636-5.

This reply refers to the comment available online at https://doi.org/ 10.1007/s40265-022-01681-8.

Mario Gennaro Mazza

mazza.mariogennaro@hsr.it

1 Psychiatry and Clinical Psychobiology, Division of Neuroscience, Dipartimento di Neuroscienze Cliniche, IRCCS Scientific Institute Ospedale San Raffaele, San Raffaele Turro, Via Stamira d'Ancona 20, 20127 Milan, Italy

2 Vita-Salute San Raffaele University, Milan, Italy

3 University Psychiatric Hospital Campus Duffel, Duffel, Belgium

4 Collaborative Antwerp Psychiatric Research Institute, University of Antwerp, Antwerp, Belgium

5 Mood Disorders Unit, Scientific Institute IRCCS Ospedale San Raffaele, Milan, Italy studies [2-4] have a sound methodology and provide pivotal findings for the clinical management of COVID-19, none of them has investigated if the beneficial effect of fluvoxamine on COVID-19 prognosis may be mediated by its direct antidepressant effect.

SARS-CoV-2 infection is associated with an immediate psychopathological distress, resulting in clinical depression in one in three patients during the early phases of the disease [6]. The underlying mechanisms are most likely related to the COVID-19-associated systemic inflammation. High interleukin- $1 \beta$ and C-reactive protein levels, and neutrophilto-lymphocyte ratio and systemic immune-inflammation index contribute to the pathophysiological onset of depressive symptoms soon after infection [7, 8]. Notably, depressive symptomatology is independently associated with an increased risk of hospitalization, intensive care unit admission, need for mechanical ventilation, and in-hospital mortality in pneumonia and respiratory diseases [9-11]. Even in COVID-19, comorbid depression was found to be associated with an increased risk of hospitalization, intensive care unit admission, and mortality [12, 13]. In contrast, antidepressant treatments have been associated with reduced all-cause mortality in the general population, and interventions for depression integrated into medical care settings have been shown to reduce hospitalization and related healthcare costs $[9,14]$.

In this context, we believe that the effect of fluvoxamine on depressive symptomatology should be investigated as a parallel relevant mechanism in improving COVID-19 hospitalization and severe outcome. A rapid improvement of depressive symptoms can be observed already in the first week of fluvoxamine administration [15]. In COVID-19, fluvoxamine serotoninergic (5-HT) and anti-inflammatory properties can be particularly effective in counteracting the depression onset rapidly triggered by SARS-CoV-2 infection-related systemic inflammation. Moreover, fluvoxamine could directly neutralize the indoleamine 2,3-dioxygenasemediated detrimental effects of inflammation by potentiating 
5-HT neurotransmission, modulating tryptophan metabolism, and reducing the excitotoxic quinolinic acid [16]. In line with these hypotheses, we found preliminary evidence of a rapid antidepressant effect of a wide range of selective serotonin reuptake inhibitors in post-COVID depressive episodes [17]. We also observed that treatment with cytokine-blocking agents during acute COVID-19 showed a protective effect against depression, proportional to the dampening of systemic inflammation [18]. Moreover, while our recent meta-analytic evidence showed a higher risk of COVID-19 severe outcome in mood disorders, pre-existing antidepressant treatment was not significantly associated with a worse prognosis [12].

Given the importance of the topic, further investigations are needed to explore whether the direct antidepressant effect of fluvoxamine could reduce the risk for a vicious cycle of infection, inflammation, depression, hospitalizations, and poor prognosis not only in COVID-19, but also in other medical conditions involving similar pathopsychological processes. Thus, considering that several studies exploring the efficacy of fluvoxamine for the treatment of SARSCoV-2 infection are still ongoing [1], we recommend all clinical trials of serotonergic compounds repurposed against COVID-19 to assess depressive symptomatology at baseline and follow-up assessments.

\section{Declarations}

Funding No sources of funding were received for the preparation of this letter.

Conflicts of interest/competing interests MGM, BV, LDP, FB, and RZ have nothing to declare.

Ethics approval Not applicable.

Consent to participate Not applicable.

Consent for publication Not applicable.

Availability of data and material Not applicable.

Code availability Not applicable.

Author contributions All authors contributed equally to this letter.

\section{References}

1. Facente SN, Reiersen AM, Lenze EJ, Boulware DR, Klausner JD. Fluvoxamine for the early treatment of SARS-CoV-2 infection: a review of current evidence. Drugs. 2021;81:2081-9. https://doi.org/10.1016/j.jval.2019.02.004.

2. Lenze EJ, Mattar C, Zorumski CF, Stevens A, Schweiger J, Nicol GE, et al. Fluvoxamine vs placebo and clinical deterioration in outpatients with symptomatic COVID-19: a randomized clinical trial. JAMA. 2020;324:2292-300. https://doi.org/10. 1001/jama.2020.22760.

3. Reis G, dos Moreira-Silva S, Eduardo A, Silva DCM, Thabane L, Milagres AC, Ferreira TS, et al. Effect of early treatment with fluvoxamine on risk of emergency care and hospitalisation among patients with COVID-19: the TOGETHER randomised, platform clinical trial. Lancet Glob Health. 2022;10(1):e42-51. https://doi.org/10.1016/S2214-109X(21)00448-4.

4. Seftel D, Boulware DR. Prospective cohort of fluvoxamine for early treatment of coronavirus disease 19. Open Forum Infect Dis. 2021;8: ofab050. https://doi.org/10.1093/ofid/ofab050.

5. Omori IM, Watanabe N, Nakagawa A, Akechi T, Cipriani A, Barbui C, et al. Efficacy, tolerability and side-effect profile of fluvoxamine for major depression: meta-analysis. J Psychopharmacol. 2009;23:539-50. https://doi.org/10.1177/0269881108 089876.

6. Schou TM, Joca S, Wegener G, Bay-Richter C. Psychiatric and neuropsychiatric sequelae of COVID-19: a systematic review. Brain Behav Immun. 2021;97:328-48. https://doi.org/10.1016/j. bbi.2021.07.018.

7. Mazza MG, de Lorenzo R, Conte C, Poletti S, Vai B, Bollettini I, et al. Anxiety and depression in COVID-19 survivors: role of inflammatory and clinical predictors. Brain Behav Immun. 2020;89:594-600. https://doi.org/10.1016/j.bbi.2020.07.037.

8. Hu Y, Chen Y, Zheng Y, You C, Tan J, Hu L, et al. Factors related to mental health of inpatients with COVID-19 in Wuhan, China. Brain Behav Immun. 2020;89:587-93. https://doi.org/10. 1016/j.bbi.2020.07.016.

9. Davydow DS, Hough CL, Zivin K, Langa KM, Katon WJ. Depression and risk of hospitalization for pneumonia in a cohort study of older Americans. J Psychosom Res. 2014;77:528-34. https://doi.org/10.1016/j.jpsychores.2014.08.002.

10. Kao L, Liu S, Lin H, Lee H, Tsai M, Chung S. Poor clinical outcomes among pneumonia patients with depressive disorder. PLoS ONE. 2014;9: e116436. https://doi.org/10.1371/journal. pone. 0116436.

11. Papaioannou AI, Bartziokas K, Tsikrika S, Karakontaki F, Kastanakis E, Banya W, et al. The impact of depressive symptoms on recovery and outcome of hospitalised COPD exacerbations. Eur Respir J. 2013;41:815-23. https://doi.org/10.1183/ 09031936.00013112.

12. Vai B, Mazza MG, Delli Colli C, Foiselle M, Allen B, Benedetti $\mathrm{F}$, et al. Mental disorders and risk of COVID-19-related mortality, hospitalisation, and intensive care unit admission: a systematic review and meta-analysis. Lancet Psychiatry. 2021;8:797812. https://doi.org/10.1016/S2215-0366(21)00232-7.

13. Ceban F, Nogo D, Carvalho IP, Lee Y, Nasri F, Xiong J, et al. Association between mood disorders and risk of COVID-19 infection, hospitalization, and death: a systematic review and meta-analysis. JAMA Psychiat. 2021;78:1079-91. https://doi. org/10.1001/jamapsychiatry.2021.1818.

14. Krivoy A, Balicer RD, Feldman B, Hoshen M, Zalsman G, Weizman A, Shoval G. Adherence to antidepressants is associated with lower mortality: a 4-year population-based cohort study. J Clin Psychiatry. 2016;77:e566-72. https://doi.org/10. 4088/JCP.14m09531.

15. Taylor MJ, Freemantle N, Geddes JR, Bhagwagar Z. Early onset of selective serotonin reuptake inhibitor antidepressant action: systematic review and meta-analysis. Arch Gen Psychiatry. 2006;63:1217-23. https://doi.org/10.1001/archpsyc.63.11.1217.

16. Eskelund A, Li Y, Budac DP, Müller HK, Gulinello M, Sanchez C, Wegener G. Drugs with antidepressant properties affect tryptophan metabolites differently in rodent models with depression-like behavior. J Neurochem. 2017;142:118-31. https://doi. org/10.1111/jnc. 14043. 
17. Mazza MG, Zanardi R, Palladini M, Rovere-Querini P, Benedetti F. Rapid response to selective serotonin reuptake inhibitors in post-COVID depression. Eur Neuropsychopharmacol. 2021;54:1-6. https://doi.org/10.1016/j.euroneuro.2021.09.009.
18. Benedetti F, Mazza M, Cavalli G, Ciceri F, Dagna L, RovereQuerini P. Can cytokine blocking prevent depression in COVID19 survivors? J Neuroimmune Pharmacol. 2021;16:1-3. https:// doi.org/10.1016/S2215-0366(20)30203-0. 